By ARTHUR B. BERTHOLD

\title{
The Future of the Catalog in Research Libraries
}

$\mathrm{A}^{\mathrm{LL} \text { OF US are more or less familiar with }}$ $A$ the various schemes for making the United States self-sufficient in regard to research materials. Without going into detail, they may be summarized into three types of proposals: (I) plans for finding out and evaluating what is already possessed; (2) plans for acquiring material as yet unavailable in the country; and (3) plans for organizing existing and to-beacquired materials to best advantage for purposes of research. In regard to the first, considerable progress has been made within the past few years. Everything that has been done in the matter of union catalogs, union lists, studies of resources of special areas, and similar undertakings has brought librarians nearer to a full understanding of research resources. It was inevitable, however, that as they became better acquainted with what they had they would discover the serious gaps in their collections. Plans were already under way just before the war to fill in these gaps by means of intensified acquisitional programs by a number of the larger research libraries. So that the financial burden would not be too great to any one of the participating libraries, each library was to aim at a complete coverage in one or a few related fields only. The war put an unavoidable stop to this, but it had the one advantage of thoroughly converting some libraries to the scheme which in the prewar period had continued to hold

1 Paper given before the Chicago Regional Group of Catalogers, Feb. 4, 1946. out in certain respects for individual action. At the moment opposition has practically disappeared and only certain details of procedure remain to be developed.

The two problems just mentioned are not of direct concern to the cataloger. They will affect his work, but largely only from the point of view of quantity. The third problem, that of organizing existing and tobe-acquired materials for purposes of research, is mainly a cataloger's problem. Apropos this problem certain theories regarding the future trend in cataloging may be advanced.

Although it has been said before, it apparently needs to be repeated that the dictionary catalog is a public library tool and that as such it has no proper place in a research library. The dissatisfaction with the dictionary catalog is no news. The agitation, a few years ago, for the separation of it into an author or main-entry catalog and a subject catalog is a clear indication of the trend of thought. This is, however, a compromise only slightly better than the original. The trouble is not so much with the dictionary arrangement as with the principle of the alphabetical arrangement in general. It seems highly illogical that while we are strict in maintaining a classed arrangement of the books themselves and clearly recognize the advantages of subject grouping over that of the alphabetical on the shelves, we do not recognize the same advantages in a classed catalog as a guide to a library's resources. 


\section{Author Catalog Only}

Generally speaking, the research library has a public which approaches the library either to obtain a specific publication or to find out what the library has on a given subject. To obtain a specific publication, the author or main-entry catalog with occasional aid from a bibliography is all that is necessary. Six years of work with the Philadelphia Union Catalogue has convinced the writer that this is not overstating the case. On the other hand, when the inquiry is about a subject, the usual entries under subject headings are an irritation rather than an answer to the researcher. This does not deny the obvious fact that when the question is about a specific subject and the library has the material it would not be listed under an appropriate heading. This. would certainly be done. But that is only part of the story. And even when one has tracked down all the "see" and "see also" references it is still true that only the standard and the more obvious publications would have been located. This may be all very well for the casual reader, but certainly it will fail to satisfy the scholar. For research only begins where the known and the obvious ends.

The popular notion that the arbitrary order of the alphabet is better understood than the logical one of classification is more than questionable when applied to the researcher. His whole training and the success of his investigations is conditioned and dependent upon order and logic, upon relation and subordination, and his particular problem is always conceived and defined in reference to other fields and problems. Classification is the first step in his work and even though it is quite true that a scholar may have slight respect for library classification systems he generally recognizes order when he sees it. It will be an aid rather than a hindrance to his work if he is required to translate his system into that of the library. The advantage of thus being in a position to go both forward or backward from his original starting point in the classification ought to be a sufficient compensation for any inconvenience he may have had in becoming acquainted with another besides his own classification system. Only the classed catalog provides one with the advantage of a thorough exploration of a given field, both vertically from the general to the specific and horizontally from the fundamental and basic type of material to the secondary and the interpretative.

\section{Two Catalogs in Future}

The research library of the future is likely to have two catalogs, an author or main-entry one and a classed catalog. The author catalog will give only such details as may be necessary to identify and to locate a particular work. As the union catalogs indicate, the entries need not go beyond the fulness of entries now accepted as sufficient for the various published checklists and short-title catalogs and the Union List of Serials. This will be quite sufficient for all practical purposes, for when a publication itself becomes an object of bibliographical study no scholar is likely to accept the cata$\log$ entry in place of an examination of the publication itself.

The second catalog and by far the most important will be the classed or systematic catalog. For reasons of economy, it is likely that the shelflist will become the basis of this catalog. The mechanics of transforming a shelflist into a classed catalog are not nearly as formidable as may appear. All that would be necessary is to assign several class marks to the same item and provide the necessary number of cards bearing these class marks and interfile them in the shelflist as it now exists. It must be understood, of course, that a call number is 
both a class mark and an identification symbol. To avoid possible confusion, each card will have the call number in the usual place and a class number in another place on the card, possibly in the upper right-hand corner. Regrouping of material from one place in the classification system to another may then be easily accomplished by a new set of cards bearing new class numbers but retaining the original call numbers. There is no need to change the original basic classification or the order of the material on the shelves. All such changes may be conveniently indicated by introducing new class marks.

\section{Use Existing Schedules as Base}

It is natural that supplementary class numbers will be selected first of all on the basis of existing subject schedules. It will be important, however, to go considerably further than this. Things don't just happen. They happen in time and in space, and it is only when these aspects are brought out clearly and unmistakably that we are able to obtain a proper perspective. A fact is understood only when it is viewed in relation to other facts, when it is defined in reference to time and place-either before or after, here or elsewhere. This introduces the problem of the historical and the geographical aspect of classification. When specific information is required, these will be the key questions to any source of information. On this score most classifications leave much to be desired. It will be the cataloger's part to make full use of the possibilities of the geography and history classes and to devise other methods when possible.

In the matter of cooperation, the cataloger will be called upon to participate on an increasingly broad scale in cooperative cataloging. This is unavoidable, especially as soon as subject specialization emerges from theory into practice. Centralized cataloging will continue to be practiced on a national scale. The Library of Congress is doing such a fine job in this field that there will be considerable hesitation before any regional or local scheme is likely to obtain the necessary support. Such regional cooperation as will develop is likely to be based upon a more thorough utilization of the union catalogs. The survey of 1940 uncovered 117 of them. Grouped by type and scope, there are:

National Union Catalogs
Regional and Local Union Catalogs
National Subject Union Catalogs
Regional and Local Subject Union
Catalogs
Exchange Union Catalogs
Library of Congress Depository Sets
Total

No subject specialization and regional selfsufficiency is possible without full development and intensive use of these tools. The problem is complicated by the fact that while numerically the net of union catalogs is quite well developed, their distribution and subject coverage is anything but logical. Much regrouping and redefining of fields and areas is necessary and when this is done the cataloger will have to do it.

Indications are that the cataloger of the future will be less of a descriptive specialist than a subject analyst. The purely descriptive operations will become less important with a fuller realization that a publication is generally more important for its contents than for its existence as a bibliographical unit. Since the subject matter is the primary consideration, it is clear that our present rather high-handed procedure with pamphlets and other occasional writings will have to be revised and approximated more nearly to the attention now given to books. It is also inevitable that the somewhat neglected practice of analytical cataloging will have to be re-established and developed further without any great regard to catalog-

(Continued on page 53) 
promotion to an administrative post. Every possible effort and device must be used to permit librarians of all ranks and in all positions to develop as rapidly and as fully as their professorial colleagues.

\section{Scholarship in Profession}

There is a significant lesson to be learned from our observation of whence arises the bulk of solid scholarship and professional research in the field of librarianship. It comes from librarians who have left their positions for a year or two to engage in graduate study and research; it comes from instructors in library schools; it comes from professional leaders who have managed to liberate themselves from the administrative details of their work and perhaps have been able to command the assistance of a staff member or two in their productive research ; it comes from that small group of inexhaustibles whom no vocational load could prevent from doing sustained intellectual work.

If all else is agreed upon, then let us deliberately devote our efforts to the solu- tion of the problem of staffing and division of labor. Perhaps we are planning services beyond what our colleges think they need and are willing to pay for. A little service contraction may bring the point more forcefully to college administrators. By maintaining myriads of departmental libraries, fraternity and dormitory libraries, browsing rooms, and instructors' working collections, we earn the same kind of condescending gratitude that faithful servants receive from their employers. When we run reserve reading rooms with the smoothness of a well-oiled machine, our clerical efficiency rating rises. These are but examples of our activities which, desirable as they are, earn for us the dubious distinction of being "such accommodating people."

Self-preservation may demand depriving our college teachers of some of the comforts to which we have been accustoming them. They have been taking all of these luxuries for granted and have recognized them as mere scaffolding. Perhaps they need the experience of trying to paint a high ceiling without a scaffold.

\section{The Future of the Catalog}

\section{(Continued from page 22)}

ing cost. If savings are to be effected, they cannot be effected at the expense of subject approach. The situation may change if and when more, and more adequate, subject indexes, bibliographies, and abstracts are regularly published.

All that has been said tends to stress the increasing importance of the cataloger in the research library of the future. It is evident that much more analytical skill and subject background will be required of him than is now the case. Furthermore, he will have to be not only thoroughly acquainted with the fields of specialiżation of his own library but it will also be part of his work to watch out for any possible trends and changes of point of view in related fields. As a first intermediary between the incoming material and the scholar, the cataloger is no less concerned with the service aspects of the library than the reference librarian. $\mathrm{He}$ should be at all times informed of the research needs and new fields of interest of the library's clientele, and his outlook and habits of thought should approximate as closely as possible those of the research scholar. And when the cataloger is able to do all these things, and successfully, the difference between his profession and that of the research scholar will be one in name only. 